\title{
QUEEN'S
UNIVERSITY
BELFAST
}

\section{Sport Preparticipation Screening for Asymptomatic Atlantoaxial Instability in Patients With Down Syndrome}

Tomlinson, C., Campbell, A., Hurley, A., Fenton, E., \& Heron, N. (2018). Sport Preparticipation Screening for Asymptomatic Atlantoaxial Instability in Patients With Down Syndrome. Clinical Journal of Sport Medicine. https://doi.org/10.1097/JSM.0000000000000642

\section{Published in:}

Clinical Journal of Sport Medicine

\section{Document Version:}

Peer reviewed version

Queen's University Belfast - Research Portal:

Link to publication record in Queen's University Belfast Research Portal

\section{Publisher rights}

(c) 2018 Wolters Kluwer Health. This work is made available online in accordance with the publisher's policies. Please refer to any applicable terms of use of the publisher.

\section{General rights}

Copyright for the publications made accessible via the Queen's University Belfast Research Portal is retained by the author(s) and / or other copyright owners and it is a condition of accessing these publications that users recognise and abide by the legal requirements associated with these rights.

Take down policy

The Research Portal is Queen's institutional repository that provides access to Queen's research output. Every effort has been made to ensure that content in the Research Portal does not infringe any person's rights, or applicable UK laws. If you discover content in the Research Portal that you believe breaches copyright or violates any law, please contact openaccess@qub.ac.uk. 


\section{Sport pre-participation screening for AAI in Down Syndrome patients}

\section{Position Statement}

\section{Introduction}

Down Syndrome (DS) is a clinical syndrome comprising of typical facial features and various physical and intellectual disabilities due to extra genetic material on chromosome 21 , with one in every 1,000 babies born in the UK affected (1). DS patients are at risk of atlanto-axial instability (AAI) although AAI can occur in other conditions, such as rheumatoid arthritis, but this position statement deals specifically with DS patients and asymptomatic AAI.

AAl, also referred to as atlanto-axial subluxation, is defined as increased movement between the $1^{\text {st }}$ (atlas) and $2^{\text {nd }}$ (axial) cervical vertebra joint articulation, the atlantoaxial joint (2). AAI in DS patients is due to a combination of ligament laxity and bony abnormalities of the atlantoaxial joint. AAl is reported to occur in $6.8-27 \%$ of the DS population (3) (4) although this varies depending on the age of the patients which you are screening. Less than $1-2 \%(3)$ (5) of these patients are then thought to later develop symptomatic AAl although the natural history and progression of AAl is not well understood (2).

The risks associated with AAI are neurological injury from excessive movement of the cervical vertebra impinging on and then damaging the spinal cord although the risk of this during sporting activities is extremely rare (2) (6). Clearly physical activity and sports participation for DS patients has many biological, psychological and social benefits (7) and the Faculty of Sport and Exercise Medicine (FSEM), United Kingdom (UK) wish to promote safe physical activity and sport for all. The FSEM, UK has therefore produced a statement regarding sport pre-participation screening for asymptomatic AAI in DS patients.

\section{Plain lateral cervical spine radiography as a screening test for asymptomatic AAI}

1. Cremers et al (6) followed up 91 asymptomatic AAl patients for 1 year after screening them with lateral cervical spine radiography, letting them either participate in unrestricted sport or restricting their sporting activities. They found no difference between the groups in terms of motor or neurological function. They concluded that there is no evidence to support plain radiography screening for asymptomatic AAI.

2. There are diagnostic inconsistencies surrounding asymptomatic AAI on plain radiography, with, for example, Morton et al (8) reporting that it occurs at $4 \mathrm{~mm}$ whilst other authors $3 \mathrm{~mm}$ (9) (10) and some $4.5 \mathrm{~mm}$ (5). 
3. AAl diagnosis on plain xray can also change as the patient gets older (4): in 1986 Morton et al (8) followed up 90 children aged between 4-19 yo for 5 years after screening them with plain cervical $x$-ray and overall the AAI prevalence decreased at follow-up.

4. Obtaining plain lateral cervical spine radiography and then the necessary measurements for AAl is technically difficult (6).

5. Symptomatic AAI is rare in DS patients (2).

6. Plain lateral cervical spine radiography (including neutral, flexion and/or extension views) cannot therefore be recommended as a screening test for asymptomatic AAl in sport (10) (6) (8) (2) (4).

\section{Alternative sport pre-participation screening techniques for asymptomatic AAI}

- For sport pre-participation assessment, a focused history and neurological examination of DS patients should be undertaken by an appropriately qualified medical professional or chartered physiotherapist (6) (4), with the preference for the professional to be someone who cares for the patient regularly, on an ongoing basis and is therefore aware of their baseline function (6), e.g. General Practitioner (GP)/Family Physician.

- Selby et al (10) conclude that both plain x-ray and physical examination are insensitive for screening for AAI in DS patients.

- For the neurological examination, Morton et al advise (8) checking for gait disturbance, neck movements, tendon reflexes, and plantar responses. This is similar to British Gymnastics, who have developed their own information sheet and undertake their own screening questions, with no radiological screening (11). This is also supported by Down Syndrome Association (12).

- The 3 screening questions consist of (11):

- Does the person show evidence of progressive Myopathy? Yes/No

- Does the person have poor head/neck muscular control? Yes/No

- Does the person's neck flexion allow the chin to rest on their chest? Yes/No

To help with question B, the person's neck control can be assessed by: laying the person on their back with legs straight and they are then pulled to a sitting position by their hands, with the examiner pulling them from the front (11).

Depending on the results of the neurological examination, assessment of neck control and the 3 screening questions, there will essentially be 2 options for the patient:

- Unrestricted sports participation;

- Restricted sports participation. 
- Sports considered to put DS patients at higher risk of developing symptomatic AAI include (2):
o Gymnastics including Trampolining;
o Diving,
o Butterfly stroke and diving starts at swimming;
o Pentathlon;
o Contact sports such as martial arts, rugby and soccer;
o High jump.

AAl symptoms for patients, family members, health and sport professionals to be aware of include (13) (11) (4):

- change in gait or use of arms or hands,

- change in bowel or bladder function,

- neck pain,

- stiff neck,

- head tilt,

- how the child positions his or her head,

- change in general function, or weakness.

These 'warning' symptoms need to be promoted to the general population, patients, family members and health professionals, e.g. through a public health campaign (4), to allow them to act if they identify an issue.

\section{Specific signs and symptoms for health professionals to be aware of when they are} examining a DS patient at risk of AAI include (2):

- Easy fatigability;

- Difficulties in walking;

- Abnormal gait;

- Neck pain;

- Torticollis or head tilt;

- Incoordination and clumsiness;

- Sensory deficits;

- Spasticity;

- Hyper-reflexia;

- Clonus;

- Extensor-plantar reflex;

- Other upper motor neuron and posterior column signs and symptoms.

\section{Acute management of symptomatic AAI}


If you suspect symptomatic AAI, the patient's spine should be immobilized and an urgent assessment, including neurosurgical consult, undertaken within the Emergency department along with MRI spinal imaging (5).

\section{Promoting safe sport for DS patients}

To facilitate safe sport for DS patients we need to promote neck conditioning exercises for this cohort of patients, similar to the neck programme promoted in patients with chronic neck discomfort (14), as well as safe sporting practices, e.g. appropriate supervision when undertaking higher risk sports such as trampolining or rugby.

\section{Conclusion}

Plain radiography cannot be currently recommended to screen for asymptomatic AAI. DS patients undergoing a sport pre-participation screening should have 3 questions asked as per the British Gymnastics programme and a neurological and neck control assessment undertaken. Neck conditioning exercises should be generally promoted amongst the DS population. Awareness of potential signs and symptoms of symptomatic AAI need to be raised amongst DS patients, family members and professionals caring for this group of patients as well as the need to provide appropriate supervision when DS patients are undertaking certain 'high-risk' sports. These measures will then allow DS patients to maximise the biological, social and psychological benefits of physical activity and sport participation.

Keywords: Down Syndrome, sport pre-participation screening, atlanto-axial instability, atlanto-axial subluxation.

Sources of Funding: No sources of funding were used when compiling this position paper.

Competing interests: Nil declared.

\section{Conflicts of Interest/Disclosures: Nil}

Ethical Approval: Not required.

Authors' contributions: NH led the conception and design of the position paper and prepared the first draft of the manuscript. All authors were involved in critical revisions and reviewing background reading. All authors critically reviewed the manuscript and approved the final version submitted for publication. All authors read and approved the final manuscript.

Authors: Dr Christopher Tomlinson¹; Dr Alastair Campbell2; Dr Alison Hurley3; Mr Eoin Fenton4; Dr Neil Heron $5,6,7,8$. 
Email address for correspondence: nheron02@qub.ac.uk

Affiliations: ${ }^{1}$ Sport and Exercise Medicine Physician,English Institute of Sport; ${ }^{2}$ Radiology Department, Musgrave Park Hospital, Belfast Trust; ${ }^{3}$ Radiology department, Dublin; ${ }^{4}$ Neurosurgery Department, Blackrock Clinic, Dublin; ${ }^{5}$ Dept of General Practice and Primary Care, Queen's University, Belfast; ${ }^{6}$ Centre for Public Health Research, Queen's University, Belfast; ${ }^{7}$ Centre of Excellence for Public Health Research (NI); ${ }^{8}$ Elected Council Member of the Faculty of Sport and Exercise Medicine (FSEM), United Kingdom (UK).

Address for correspondence: Dept of General Practice, Queen's University, Dunluce Health Centre, Level 4, 1 Dunluce Avenue, Belfast, BT9 7HR.

\section{References}

(1) Roizen NJ, Patterson D. Down's syndrome. The Lancet 2003 4/12;361(9365):1281-1289.

(2) Committee on Sports Medicine and Fitness. Atlantoaxial instability in Down syndrome: subject review. American Academy of PediatricsCommittee on Sports Medicine and Fitness.. Paediatrics 1995;96(1, Part 1):151-4.

(3) Nader-Sepahi A, Casey ATH, Hayward R, Crockard HA, Thompson D. Symptomatic atlantoaxial instability in Down syndrome. Journal of Neurosurgery: Pediatrics 2005 09/01; 2017/03;103(3):231237.

(4) Myśliwiec A, Posłuszny A, Saulicz E, Doroniewicz I, Linek P, Wolny T, et al. AtlantoAxial Instability in People with Down's Syndrome and its Impact on the Ability to Perform Sports Activities - A Review.. Journal of Human Kinetics 2015;12(48):17-24.

(5) Cohen W. Current dilemmas in Down syndrome clinical care: celiac disease, thyroid disorders, and atlanto-axialinstability.. American Journal of Medical Genetics 2006;142C(3):141-8.

(6) Cremers MJG, Bol E, de Roos F, van Gijn J. Risk of sports activities in children with Down's syndrome and atlantoaxial instability. The Lancet 1993 8/28;342(8870):511-514.

(7) Andriolo R, El Dib R, Ramos L, Atallah A, da Silva E. Aerobic exercise training programmes for improving physical and psychosocial health in adults with Down syndrome.. Cochrane Database of Systematic Reviews. 2010;12(5):CD005176.

(8) Morton R, Khan M, Murray-Leslie C, Elliott S. Atlantoaxial instability in Down's syndrome: a five year follow up study.. Archives of Disease in Childhood 1995;72(2):115-8.

(9) Roy M, Baxter M, Roy A. Atlantoaxial instability in Down syndromeguidelines for screening and detection.. Journal of the Royal Society of Medicine 1990;83(7):433-5. 
(10) Selby K, Newton R, Gupta S, Hunt L. Clinical predictors and radiological reliability in atlantoaxial subluxation in Down's syndrome. Archives of Disease in Childhood 1991;66(7):876-8.

(11) British Gymnastics. Atlanto-axial instability information pack. British Gymnastics 2012;1(1):1.

(12) Charleton P, Dennis J.

Neck Instability (Craniovertebral Instability)

A GUIDE FOR PARENTS AND CARERS. Down Syndrome Association Health Series 2013;1(1):1.

(13) Bull MJ, Committee on Genetics. Health supervision for children with Down syndrome.. Paediatrics 2011;128(2):393-406.

(14) Karlsson L, Gerdle B, Takala E, Andersson G, Larsson B. Associations between psychological factors and the effect of home-based physical exercise in women with chronic neck and shoulder pain. Sage Open Medicine 2016;4(2050312116668933).

(CFaculty of Sport and Exercise Medicine UK - Sport pre-participation screening for asymptomatic atlanto-axial instability (AAI) in Down Syndrome (DS) patients June 2017, to be reviewed April 2020.

\section{Terms of Use}

Position statements published by the FSEM (UK) are quick reference or information documents for the Sport and Exercise Medicine and healthcare community. They can include up to ten short points of clinical relevance and are designed to be useful short reference documents.

The FSEM (UK) will publish updates to its official position statements as and when new information is available. The current versions will appear on the website, including the date published, and will supersede and replace prior versions. FSEM UK does not circulate or endorse out of date versions of its position statements.

Our position statements are freely available to the medical and healthcare profession and are subject to copyright, if you plan to use or share them, please ensure you include an up to date version of the statement and credit the Faculty of Sport and Exercise Medicine UK. 